\title{
МЕТАМОРФОЗЫ ИДЕНТИЧНОСТИ: \\ ТРУДНОСТИ ПЕРЕВОДА
}

\section{Рецензия на книгу «Свои и чужие. Метаморфозы идентичности на востоке и западе Европы»1}

\author{
ГЛЕБ СМИДович
}

\begin{abstract}
Коллективная монография учёных России и Франции, Белоруссии и Австрии посвящена кризису идентичности. Ключевыми проблемами видятся повсеместное замещение гражданского содержания национальной идентичности ее культурным компонентом, различный подход к исследованиям идентичности на западе и на востоке Европь, динамичные и зачастую непрогнозируемые взаимоотношения между различными видами идентичности. Исследования показывают, что сегодня конструирование национальной, региональной, этнической идентичности всеми акторами (политиками, журналистами, учёными, обществом) служит основным источником кризиса идентичностей. Причина различного видения проблем трансформации идентичности когнитивный диссонанс, когда одни и те же слова имеют разные смысль на западе и востоке Европы, что во многом обусловлено историческим бэкграундом, при этом противоречия носят внешний характер, а конфликты порождаются «трудностями перевода». Задача научного сообщества - преодоление стереотипов, установление диалога с иелью поиска новых инструментов анализа и выработки новых эпистемологий, а цель книги - сделать шаг на пути преодоления подобных непониманий.
\end{abstract}

Ключевые слова: идентичность, идентификация, государства-нации, нациестроительство, национальность, гражданство, конструирование идентичностей, дискурс.

Во введении редакторы (Е. Филиппова и К. Ле Торривелек) артикулируют концептуальные рамки изучения проблем национальной идентичности, являющихся стержневой составляющей книги. Во-первых, по их мнению, имеет место повсеместное ослабление гражданского содержания понятия национальной принадлежности, компенсируемое повышенным вниманием к ее культурной составляющей, к общему прошлому. Во-вторых, традиционное расхождение в отношении к культурным различиям на западе Европы и на ее востоке, где, как мягко сказано, «этничность сохранила значимость вопреки попыткам построения национальных государств по образу и подобию Западной Европы». В-третьих, абсолютизация несходства в понимании коллективных идентичностей мешает заметить двусторонний процесс конвергенции между «гражданскими» и «культурными» нациями ${ }^{2}(3)$. При этом, в-четвертых, «дискурсы национальной идентичности, производимые политиками, журналистами, экспертным сообществом и отражаемые общественным мнением (и почти в той же мере порождаемые им) как на Востоке, так и на Западе, сближаются до неразличимости» (8).

ГЛЕБ СЕРГЕЕВИЧ СМИДОВИЧ (gleb.smidovich@gmail.com), ФЕДЕРАЛЬНЫЙ НАУЧНО-ИССЛЕДОВАТЕЛЬСКИЙ СОЦИОЛОГИЧЕСКИЙ ЦЕНТР РОССИЙСКОЙ АКАДЕМИИ НАУК, РОССИЯ.

РЕЦЕНЗИЯ ПОСТУПИЛА В РЕДАКЦИЮ В НОЯБРЕ 2019 Г.

\footnotetext{
1 (Филиппова, Ле Торривеллек 2018).

2 При цитировании или отсылке к рецензируемой книге будет даваться только номер страницы.
} 
Отмечая попытки написания альтернативных версий истории при явно недостаточном внимании к необходимости национального примирения, выработки общего проекта, авторы подчеркивают, что оборотной стороной дискурсивного конструирования нации, акцентирующего представление об ее уникальности и однородности, с одной стороны, и огромной разнице с прочими нациями - с другой, является реификация национальной идентичности (7).

Задача научного сообщества, по мнению редакторов, - в преодолении стереотипов, установлении диалога с целью поиска новых инструментов анализа и выработки новых эпистемологий, а цель книги - сделать шаг на пути преодоления подобных непониманий (3-4). Причем, судя по контексту, противопоставление «свой/чужой» авторы относят в первую очередь к представителям научного сообщества. Корень проблемы видится им в когнитивном диссонансе, в том, что одни и те же слова имеют разные смыслы на западе и востоке Европы, в том, что противоречия носят внешний характер, а конфликты порождаются «трудностями перевода». Что наталкивает читателя на старую непреложную истину: «О терминах не спорят, о них договариваются».

Не слишком усидчивый и желающий сэкономить свое время читатель может и ограничиться Введением, которое, вероятно, написано по законам жанра - постфактум. Насыщение можно гарантировать, однако для гурманов все-таки главное - вкус...

Представленные в книге тексты логично распадаются на несколько сетов: первый посвящен компаративным исследованиям - будь то анализ концептов гражданства и национальности на востоке и на западе Европы (И. Плассро, Франция) или российского и французского дискурсов о национальной идентичности (Е. Филиппова, Россия). Вторая группа статей посвящена осмыслению нации, идентичности, формирования политик конструирования наций и моделям национальной идентичности на страновом уровне (Ю. Чернявская и В. Шадурский, Белоруссия; А. Плеханов, Россия; Е. Веттер и Р. Де Силья, Австрия). Третий сет - особенностям формирования идентичности на региональном и локальном уровнях (В. Амелин и И. Габдрафиков, Россия; Р. Ле Коадик, Франция; П. Терешкович, Белоруссия; К. Гаврилова, Россия). Четвертый пласт статей, как и водится в коллективных монографиях, представляет сборную солянку исследования смежных проблем - различных аспектов формирования, трансформации и осмысления идентичности: роли территории (Я. Беван, Франция), анализа разграничения идентичности и идентификации (С. Соколовский, Россия), влияния кризиса 2008 г. на трансформацию идентичности исландцев (И. Кучерова, Россия). Но это логика рецензента, а не редакторов: статьи из разных сетов перемешаны, их последовательность обусловлена иными, не всегда понятными мотивами.

Тон дискуссии должна была задать статья И. Плассро «Гражданство/национальность на востоке и западе Европы: культурные заимствования или концептуальный тупик?», в которой исследуется эволюция концепции гражданства и национальности на востоке и западе Европы. Исторические штудии автора, касающиеся Восточной Европы и, особенно, постсоветского пространства, вряд ли задержат внимание читателя. Больший интерес представляют размышления автора о европейском гражданстве, эволюции традиционных взглядов на гражданство и национальность во Франции. Автор солидаризируется с точкой 
зрения Ф. Констана, что мир зажат в тиски и разрывается на части из-за недостаточного развития гражданского общества, с одной стороны, и разрушительного, с точки зрения самоидентификации, действия глобализации - с другой. Что страны универсалистской традиции (то бишь запада) постепенно усваивают дифференциалистскую логику, тогда как страны, традиционно придерживавшиеся дифференциалистского подхода (востока), осваивают логику универсалистскую [26]. При сем автор далек от оптимизма: «Несмотря на некоторое концептуальное сближение, пропасть, разделяющая две части континента, снова углубляется» [27].

Статья Е. Филипповой «Сначала было слово». Дискурс национальной идентичности в России и во Франции» лишена трюизмов статьи И. Плассро. Автор поставил перед собой непростую задачу: выявить сходства и различия в дискурсах национальной идентичности в России и во Франции - странах, чье понимание нации часто представляется диаметрально противоположным. В дискурсе обеих стран звучит немало общих тем: это идея величия, суверенитета, культурного богатства, славного прошлого, особой роли языка и утверждение необходимости защищать все это перед лицом глобализации, американского политического и культурного доминирования, низкопробных образцов массовой культуры, а также угроз международного терроризма.

Обе страны переживают сегодня консервативный поворот, вызванный снижением чувства защищенности. Во имя личной безопасности их граждане готовы смириться с ограничением некоторых личных свобод, что вполне ожидаемо для России, имеющей репутацию патерналистского общества, но куда менее - для Франции, чей имидж ассоциируется с бунтом и непокорностью.

Прочтение текста (когда речь идет о французских реалиях) вызывает ассоциации с реалиями российскими. Ссылка на французского социолога А. Шураки, подчеркивающего «страхи, фрустрацию, гнев, ксенофобия, расизм», напряженность в обществе на фоне «утраты ориентиров», коими служили «семья, работа и национальная общность» (104) вызывает в памяти тексты Л. Гудкова, ставящего аналогичный диагноз российскому обществу. Ссылка на Э. Макрона, относящегося к теме идентичности с большой осторожностью, поскольку она в последние годы монополизирована правым и ультраправым дискурсом, и который предпочитает говорить о «принадлежности к нации» и о «национальном нарративе» или «национальном романе»- ассоциацию с российскими дискуссиями о «цивилизационном коде».

Специальное внимание Е. Филиппова уделяет теме миграции и роли религии в формировании национальной идентичности. В дискурсе обеих стран присутствует тема миграционной угрозы национальной идентичности, обосновываемая культурной несовместимостью «местного» и «пришлого» населения. В России, да и во Франции, налицо «этнизация феномена миграции», в результате чего «конфликты, возникающие на почве конкуренции за доступ к власти и ресурсам, понимаются как проявление взаимной несовместимости» (96). При всей похожести дискурса, во Франции, в отличие от России, гораздо громче звучат голоса противников антимиграционизма, причем не только в среде интеллектуалов или активистов гуманитарных и правозащитных организаций, но и политиков леволиберального толка (98). Кроме того - и это особенно важно - 
представление о Франции как о родине концепции прав человека и стране убежища остается важнейшей составлявшей ее национальной идентичности для значительной части населения, которое регулярно мобилизуется на защиту мигрантов.

Связь религии с национальной идентичностью в России и Франции выглядит, по мнению автора, «наиболее контрастной». Применительно к национальной идентичности и религии сознание россиян по-прежнему остается секулярным, тогда как в церкви они видят, скорее, еще один институт власти, а религия рассматривается как атрибут коллективного членства (102).

Как для Франции, так и для России характерны мучительные и безуспешные поиски нового общенационального проекта. Отталкиваясь от размышлений П. Нора о том, что во Франции ни один идеологический прожект за последние полвека не смог воодушевить нацию, автор констатирует: «Из двух составляющих ренановской формулы: нация как наследие («культ предков») и нация как проект («ежедневный плебисцит») осталась лишь первая». Пессимистично? - Как посмотреть, на фоне российских реалий. Полагая, что, чтобы россияне стали ощущать себя единой нацией, необходимо, чтобы у этой нации было, в соответствии с классическим ренановским принципом, желание жить вместе, а не выживать в одиночку, автор резюмирует: «В российском дискурсе национальная идентичность предстает как идеал, к которому нужно стремиться, во Франции - как достижение, которое нужно сохранить» (103).

Статьи Ю. Чернявской («Модификации белорусской идентичности: медийность и повседневность»), В. Шадурского («Основные модели национальной идентичности в современной Беларуси»), А. Плеханова («Украинская национальная идентичность в контексте формирования национального пантеона героев»), Е. Веттера и Р. Де Силья («Как стать австрийцем? Что значит быть им? Размышления о конструировании австрийской национальной идентичности - история и современность») акцентируют внимание на процессах нациестроительства, формирования национальной идентичности в Белоруссии, на Украине и в Австрии.

Ю. Чернявская констатирует, что в самосознании значительной части белорусского общества («евробелорусов») Россия принадлежит востоку, тогда как Белоруссия - запад, хотя еще не сбросивший оковы востока. Образ России как востока (империи восточного образца, деспотии и др.) достаточно стабилен. Другая, большая часть общества занята элементарным выживанием. Именно они («белороссы») принимают риторику «трех братских народов»: эта ценность входит в их идентичность так же, как и ценность стабильности (127).

В ситуации экономической безнадежности, когда «холодильник побеждает телевизор», все более обостряется конфликт идентичностей, причем далеко не только двух названных выше - «евробелорусской» и «белоросской». «Это всего лишь темы, внутри которых существуют вариации» (128).

В статье подробно рассмотрены различные варианты идентичности, для российского читателя особый интерес представит анализ неведомой в России игровой версии этничности, из медийной сферы перекочевавшей в повседневность. 
Автор считает, что вырабатывается новая гибридная идентичность, что в следующее десятилетие налет гламура, консьюмеризма, игры, рекламы будет все более поглощать все ныне существующие виды белорусской идентичности, превращая ее в разноплановую, нечувствительную к противоречиям поп-идентичность. Однако этот status quo возможен лишь в более или менее стабильной ситуации. Этничность и тем более национальногражданская идентичность имеет пульсирующий характер, и прогнозировать ее поведение в случае украинского сценария на сегодня представляется нереалистичным (140).

В. Шадурский акцентирует внимание читателя на том, что белорусское общество сегодня разделено на четыре больших группы с различным пониманием национальной идентичности и различными стратегиями национально-государственного строительства. Их отличают подходы к оценке основных событий белорусской истории, выбору государственного языка, определению интерационных перспектив и др. Наряду с упоминавшимися Ю. Чернявской «евробелорусской» и «белоросской» моделями, в статье рассматриваются также модели «Беларусы» (партия власти)» и «Беларусы» (платформа национального согласия/компромисса)». Автор отмечает слабое выражение коллективной воли белорусской нации, ее медленную мобилизацию. В белорусском обществе попрежнему доминирует индивидуально-семейная (адаптационная) стратегия преодоления кризисных явлений. Решение собственных проблем, проблем своей семьи является первичным по сравнению с общенациональными задачами (151).

Статья А. Плеханова представляет добротный анализ научной литературы и результатов социологических обследований, проведенных ведущими украинскими социологическими центрами, отдельных нормативных правовых актов, а также результаты качественных исследований, проведенных автором на Украине.

Автор полагает, что насущная потребность проецирования на участников АТO успешного исторического опыта вооруженной борьбы потребовала активного привлечения героев националистического нарратива. В государственном дискурсе и СМИ происходит демонизация и дегуманизация образа России и личностей, представляющих общее прошлое России и Украины, а также вытеснение при помощи законодательства альтернативных националистическому исторических повествований. Каждая историческая фигура уже распределена между политическими лагерями, и собственный выбор той или иной исторической личности - это не некое личное отношение, а акт политической самоидентификации. И как резюме: «В настоящее время существуют две ключевые разнонаправленные тенденции: усиление обращения государства и его культурных индустрий к националистическому пантеону героев и общественный запрос на нейтральных героев, связанных с культурой, наукой, образованием, примиряющих, а не раскалывающих общество» (172).

Е. Веттер и Р. де Силья предуведомляют свои размышления о конструировании австрийской национальной идентичности словами: «Отправными точками этих размышлений послужат три сюжета: история проблемы идентичности, ее современное состояние и радикализация дискурса об идентичности» (177).

Характерной особенностью Австрии авторы видят то, что дискуссии об идентичности ведутся тут с давних пор в отличие, например, от Франции. Поэтому 
изучение конструирования здесь многоязычных и многокультурных идентичностей может представлять особый интерес для Европы, определяющей характеристикой которой является многообразие.

Плюралистская логика дуалистической монархии XIX века стала давать сбои в веке $\mathrm{XX}$, поскольку, с одной стороны, государство утратило способность структурировать мультиэтническое общество, а с другой - народы, соблазненные национализмом, все менее и менее были готовы договариваться о новом гегемоническом равновесии (183).

Авторы исходят из того, что национальные идентичности изменчивы, подвижны, непрочны и амбивалентны. Кроме того, контуры идентичности, предлагаемые политической элитой и СМИ, с одной стороны, и ежедневно производимые в обыденном языке - с другой, влияют друг на друга (185).

Источником проблемы, которая грозит обостриться в будущем, является деление меньшинств на автохтонные, признанные Конституцией, и пришлые меньшинства, не пользующиеся особыми правами. Тогда как первые, исходя из примордиалистских концепций, являются частью австрийской нации, вторые из нее исключаются. Это тем более проблематично, что с некоторых пор пришлые меньшинства превосходят автохтонов по численности, и эта разница постоянно растет. Национальную идентичность становится все труднее понимать и принимать в примордиалистском ключе; дифференциация на местные, пришлые меньшинства и этническое большинство в будущем может стать одной из серьезных проблем Австрии (194).

Вопросам формирования идентичности на региональном и локальном уровне посвящены статьи В. Амелина и И. Габдрафикова, Р. Ле Коадика, П. Терешковича, К. Гавриловой.

В. Амелин, И. Габдрафиков изучают формирование российской идентичности в полиэтничной среде Урало-Поволжья. Социологические замеры показывают, что у жителей Оренбурга и Уфы сформировался высокий уровень гражданской идентичности, которая для людей более значима, чем этническая и конфессиональная. Говоря о «региональной идентичности» и «региональном самосознании», авторы вольно или невольно ставят знак равенства между гражданской идентичностью и «общефедеральной лояльностью» (115).

Р. Ле Коадик анализирует дискурс региональной идентичности в Бретани и четко формулирует результаты своего исследования:

1. Коллективная идентичность бретонцев не основывается ни на едином языке, ни на преувеличенном внимании к каким-либо этническим различиям, направленном в конечном итоге на исключение Другого, но на их повседневной культуре поведения и желании жить вместе, разделяя общую судьбу.

2. Отторжение Другого - будь то иностранец или мусульманин - гораздо меньше распространено в Бретани, чем среди всего населения Франции. Бретонцем, как показывает автор, можно стать вне зависимости от наличия миграционного прошлого, гражданства, этнической принадлежности или религии. 
3. Представления бретонцев об условиях интеграции в местное сообщество являются одновременно инклюзивными и аффективными, основанными на идее разделяемого чувства.

Автор предполагает, что все эти факты являются следствием жизненного опыта населения Бретани и различных влияний, которым оно подверглось. Прежде всего а-этническая концепция бретонской идентичности не противоречит французской теории нации. Открытость по отношению к Другому согласуется и с ценностями католической культуры (в ее евангелическом, а не институциональном измерении). Можно предположить, что существование, осознанное или нет, в статусе меньшинства, поскольку чаще всего оно связано с той или иной формой непризнания данной группы в рамках государства, порождает у членов этой группы особую чувствительность к инаковости (243).

П. Терешкович изучает практику конструирования идентичностей населения западной части Белорусского Полесья. Цель, которую он ставит перед собой, продемонстрировать, каким образом различные практики классификации населения (статистические, административные, этнографические и лингвистические) работают в условиях культурного пограничья.

На настоящий момент, по его мнению, выделяются по меньшей мере четыре варианта идентичностей Белорусского Полесья, причем как научный лингвоэтнографический дискурс, так и статистические материалы предлагают достаточно широкий набор аргументов в пользу каждой из них. В украинском проекте все коренное население западного белорусского Полесья априорно рассматривается как украинское. В идеологии ятвяжского проекта центральное место занимает миф происхождения полешуков от раннесредневекового балтского племени ятвягов, независимого ятвяжского государства. Берестянский проект предлагает вариант региональной идентичности, при котором в категорию «берестяне» включены все группы местного населения, включая ятвягов, бужан, украинцев, белорусов, «тутейших». Вариант белорусской идентичности выступает прежде всего в форме идентичности гражданской, но не исключающей этнокультурного компонента. И несмотря на негативный шлейф брутальности поголовного директивного превращения полешуков в белорусов, белорусская идентичность в регионе, появившаяся задолго до 1939 г., не является искусственной.

Одновременное соотнесение с Белоруссией и слокальными и/или украинскими этнокультурными особенностями во многом и сегодня характерно для массовой идентичности населения западной части белорусского Полесья. При этом кажущаяся на первый взгляд абсурдной практика пограничья, превращающая смену идентичности в обыденность, позволяет не только выбирать между ними, но и абсолютно непротиворечиво сочетать их: можно быть одновременно или попеременно и украинцем, и белорусом, полешуком-украинцем или полешуком-белорусом, ятвягом, берестянином и т.д. (265).

Статья К. Гавриловой, туманно-чудно и необъяснимо озаглавленная «5+ жизней одной спорной категории: Чуди на Пинеге и в окрестностях» посвящена истинному чудотворству - конструированию этничности из ничего. Автор пишет, что «изначально 
задуманная статья о курьезе постсоветской этнической практики трансформировалась в исследование о том, как несколько «жизней» спорной категории делают перекодировку фольклорного персонажа в этнического агента возможной и даже логичной». В статье показано, как формировался образ живой этнической группы (о которой на Пинеге никто не имел представления) при помощи узнаваемого набора показателей этничности: исторического нарратива, географии расселения, языка, уникальной религии и специфических культурных практик (306).

В рассматриваемом случае знание очередным О. Бендером схем концептуализации и манифестации этнической группы, ставших практически универсальными благодаря советской национальной политике, позволило сформировать убедительный образ автономной этнической группы, обладающей историей, территорией, специфической материальной культурой, языком и даже религией (327).

Казалось бы, ну казус, ну оригинальный, фантастический кейс, очень забавное и интересное описание, но чем вызвана необходимость публикации текста такого объема, с которым редкому читателю совладать (67 страниц)? На кого текст рассчитан? Но это вопрос к редакторам, а не автору.

В статье «Идентичность и идентификация: к расширению программы антропологических исследований» С. Соколовский ставит задачей расширение стандартного круга вопросов, используемого в исследованиях идентичности антропологами и их коллегами из смежных социальных наук: социологии, психологии и философии. Автор отделяет метафизическое, рефлексивное определение идентичности от материальной тождественности, пытаясь заполнить лакуны в полевых этнографических исследованиях (29), связанные с разницей в подходах к их определению в разных науках. Рассматриваются различные регистры идентичности, разность языкового употребления и применения этого термина в различных сферах, в том числе экономике и цифровой идентичности, отделяя её от ментальной, т.е. самоидентиифкации. Эта категория предстаёт как фиксированной, имманентной, так и текучей, изменчивой, что задаёт горизонт для дальнейших антропологических исследований (40). Также демонстрируется использование акторно-сетевой методологии (ANT-подход) в антропологии идентичности. Интересная, вызывающая вопросы статья (насколько правомерно, например, отнесение к социальным идентичностям таких понятий, как честность, порядочность, правдивость или справедливость?), все-таки видится выпадающей из общего корпуса книги. Боюсь, что эта глубокая и артистически оформленная статья окажется не по зубам многим читателям - уж больно она специальна и, скорее, оказалась бы более уместна в научном журнале.

Я. Беван, автор статьи «Идентичность и территория: к вопросу об их идеологическом использовании», приходит к выводу, что главную проблему современного мира составляет не столько столкновение культур, сколько территориализация идентичностей, порождающая соперничество и противостояние. Отмечена парадоксальность понятия «идентичность», выведенная философом Ф. Декомбом: на западе она считается индивидуальной характеристикой, хотя и выражается в чувстве принадлежности индивида к коллективу. Однако рассмотрение ее как коллективного чувства означало бы отрицание 
свободной воли индивида. И в том, и в другом случае территориализация остается фактором, который нельзя обойти стороной (63).

Автор констатирует, что главную проблему современного мира составляет не столько столкновение культур, сколько территориализация идентичностей, реальных или воображаемых, и именно эта территориализация порождает соперничества и противостояния (58). Я. Беван солидаризируется с другим автором книги: «процесс детерриториализации идентичности - то, что Р. Ле Коадик называет «нацией в сердце» возможен лишь при условии, что эта идентичность достаточно уверена в себе, умиротворена, признана, а на ее «идеальную территорию» никто не покушается (65).

И. Кучерова изучает изменение идентичности исландцев под влиянием кризиса 2008 г. сквозь призму концепта удаленности, выступающего не только и не столько географической, сколько социальной характеристикой, отличительной чертой которой является противопоставление центру (удаленность всегда относительна) и парадоксальная замкнутость «изнутри», сочетающаяся с открытостью внешнему миру.

Автор полагает, что кризис 2008-2011 гг. вновь передвинул Исландию по шкале «нормальная европейская/скандинавская страна - дикая, экзотическая страна» в сторону последней. Исландия, имеющая долгую историю восприятия ее другими как удаленной колонии, столь же долго старалась «приблизиться» к центру, заняв достойное место среди европейских стран, значительную часть времени находясь на границе между дикостью и цивилизацией, историей и современностью, категоризируясь в зависимости от ситуации, интересов и политических целей (220).

Потоки туристов, с одной стороны, «приближают» ее, принося с собой стандартные туристические практики, с другой - (так как иностранцев привлекает именно удаленность) они соответствующим образом формируют восприятие Исландии (в том числе и самими исландцами) как «экзотической» страны, следуя привычным стратегиям колониального дискурса. Пока прибытие туристов усиливает «пограничность» Исландии: между Европой и США, между природой и культурой, локальностью и глобальностью; а что будет дальше, вероятно, зависит от того, как сами исландцы готовы воспринимать свою страну (222).

Было бы странно отсутствие недочетов в столь фундаментальной и интересной работе. Смущает, что процессы нациестроительства на Украине и трансформации идентичности в Исландии исследуют российские авторы: это может быть очень глубоко и содержательно, но все-таки - взгляд со стороны. Не менее смущает чудовищно большой текст, посвященный не столь уж значимой проблеме формирования идеологемы о чудской идентичности. Жалко, что этим текстом редакторы завершают книгу, - напрашивается заключение, подытоживающее результаты проекта.

Но все это ничто, перед тем, что объединяет авторов и их взгляды. Уже приходилось упоминать об ассоциациях с российской действительностью по прочтению статей французских авторов. Но есть и сквозные, опорные образы, поднимаемые самыми разными авторами: это и неоднократно упоминаемый тезис Ренана о плебисците, это и его же утверждение о необходимости «забвения» любой другой идентичности, которая может помешать идеологической интеграции, а может быть, и искажения исторической правды, 
если таковое потребуется для укрепления идеологического фундамента нации и придания ей темпоральной легитимности, и тезис, что определенный дискурс, обращение к тем или иным историческим фигурам уже само по себе является одним из маркеров идентичности.

Единственным вопросом, не вызывающим разночтений у авторов из разных стран, является язык, который является оселком идентичности и который по преданию стал инструментом разобщения в Вавилоне.

Ассоциация с Вавилонской башней - не только констатация проблем общественных дискуссий об идентичности в каждой стране, рассматриваемой авторами книги, но и проблем взаимопонимания между специалистами Западной и Восточной Европы. Трансформация идентичности во всех ее проявлениях, равно как и дискурсы об идентичности - продукт меняющихся социально-экономических, политических и культурных сред. Тогда как дихотомия свои/чужие во многом зависит от исследователей. Эти категории, конструируемые наблюдателем, подобно коту Шредингера одновременно существуют и как бы их нет - это в первую очередь зависит от набора критериев их выделения. Устранение недопониманий, трудностей перевода должно повернуть вспять процесс саморазрушения, направить нациестроительство, укрепление национального самосознания и национально-гражданской идентичности в конструктивное, созидательное русло.

\section{ЛИТЕРАТУРА}

Филиппова Е.И., Ле Торривеллек К. (Ред.) (2018). Свои и чужие. Метаморфозы идентичности на востоке и западе Европы. М.: Институт этнологии и антропологии им. Н. Н. Миклухо-Маклая РАН, Горячая линия - Телеком. ISBN 978-5-9912-0783-6. 


\section{IDENTITY METAMORPHOSIS:}

\section{LOST IN TRANSLATION}

\section{Review of the book «Us and them. Identity metamorphosis in Eastern and Western Europe» \\ GLEB SMIDOVICH}

The book, a collective monograph by researchers from Russia and France, Belarus and Austria, is devoted to the identity crisis. The key problems are considered to be the widespread substitution of the civil content of national identity with its cultural component, the different approach to identity research in Western and Eastern Europe, and the dynamic and unpredictable relationships among different kinds of identity. Research shows that today the main cause of the identity crisis is the construction of national, regional, and ethnic identities by all actors (politicians, journalists, researchers, society). The origin of the problem is in the cognitive dissonance resulting from the different meanings of the same words used to describe identity transformation in Western and Eastern Europe. Such difficulties are mostly external by nature and are based on the historical background and "lost in translation" conflicts. The task of the scientific community is to overcome stereotypes and to establish a dialogue with a view to finding new tools to analyze and develop new epistemologies, while that of the book's contributors is to take a step towards overcoming such misunderstandings.

Key words: identity, identification, nation state, construction of a nation, nationality, citizenship, construction of identities, discourse.

Gleb SMidovich (gleb.smidovich@gmail.com), FedERAL CENTER of TheORETICAL ANd APPlied Sociology OF THE RUSSIAN ACADEMY OF SCIENCES, RUSSIA.

DATE RECEIVED : NOVEMBER 2019.

\section{REFERENCES}

Philippova E.I., Le Torrivellec X. (Eds.) (2018). Us and them. Identity metamorphosis in Eastern and Western Europe. Moskow: Institut etnologii i antropologii im. N. N. Miklukho-Maklaya RAN, Goryachaya liniya - Telekom. (In Russ.). ISBN 978-5-9912-0783-6. 